\title{
FATORES GERADORES DE COMPETITIVIDADE NA MANUFATURA: UMA RELAÇÃO ENTRE PRÁTICAS E RESULTADOS
}

\author{
FACTORS THAT GENERATE COMPETITIVENESS \\ IN MANUFACTURING: A RELATIONSHIP \\ BETWEEN PRACTICES AND RESULTS
}

\author{
Recebido - 19.10.2010 \\ Aceito - 14.04.2011 \\ Janaina Piana ${ }^{1}$ \\ Rolf Hermann Erdmann²
}

\begin{abstract}
Resumo
A dimensão global da competição exige que as empresas sejam administradas sob perspectivas que levem em consideração a integração entre as áreas da organização. Para tal, é necessário observar quais são as prioridades competitivas que afetam essas áreas. Objetiva-se, através de uma pesquisa documental, identificar os fatores geradores de competitividade às organizações. Os resultados se consolidaram em 107 fatores. Estes foram classificados em 14 grupos: Produção enxuta, benchmarking, relacionamento com clientes, tecnologia, integração, responsabilidade ecológica, informação, flexibilidade, custo, qualidade, inovação, confiabilidade, treinamento e rapidez. Com isso, analisou-se a inter-relação entre eles através de uma visão de práticas e resultados.
\end{abstract}

Palavras-chave: Competitividade. Prioridades Competitivas.

\footnotetext{
1 Mestranda, Programa de Pós-Graduação em Administração, Universidade Federal de Santa Catarina (UFSC). Brasil. E-mail:, janainapiana@hotmail.com.

2 Professor Dr., Departamento Sócio-Econômico, Universidade Federal de Santa Catarina (UFSC). Brasil. E-mail: erdmann@cse.ufsc.br.
} 


\begin{abstract}
The current context and rapid change a lot of possibilities of decisions organizational environment becomes more complex. The global dimension of competition requires that companies will be administered under a new perspective that relations between the different areas of the organization. To this end, it is necessary to observe which are competitive surrounding priorities on the areas and leading the Organization to achieve higher levels of competitiveness. This work, through a vast documentary research in books, journals and Annals, installed a waiver in respect of the main priorities competitive. The consolidated results in 100 (one hundred and thirteen) items generators of competitiveness. These were classified into 14 (fourteen) groups: Lean Production, Benchmarking, Customer Relations, Technology, Integration, Eco Responsibility, Information, Flexibility, Cost, Quality, Innovation, Reliability, Training and Speed. Still, examined the interrelation between them through a vision of practices and outcomes. From this conclusion future objective studies for the use of these items or factors in the development of an organizational diagnostic tool that takes into account the complex relations of a production system.
\end{abstract}

Keywords: Administration of Production. Theory of Complexity and Competitive Advantages.

\title{
1 INTRODUÇÃO
}

A dimensão global da competição tem exigido que as empresas industriais passem a administrar a manufatura sob uma perspectiva que leve em consideração as relações entre as diferentes áreas da organização. Para tanto, é necessário observar quais são as prioridades competitivas que circundam sobre as áreas e que levam a organização a atingir patamares superiores, remetendo, dessa forma, a busca constante de práticas que gerem vantagem competitiva à organização.

Devido a isso, constatou-se a necessidade de buscar, na literatura da Administração, características ou aspectos essenciais para a geração de competitividade nas organizações, como forma de prepará-las para que antevejam as não linearidades do ambiente.

\section{PRIORIDADES COMPETITIVAS}

As prioridades ou vantagens competitivas podem ser definidas como um conjunto consistente de características de desempenho que a empresa terá e através da qual contribuirá para um aumento da competitividade da organização (CASTRO; SANTOS; SILVA, 2008).

Esse conceito, segundo Castro, Santos e Silva (2008), tornou-se relevante na produção após o trabalho de Skinner (1969), que apontou padrões comuns para mensurar o desempenho da manufatura. Skinner (1969) demonstrou as seguintes características: atender a ciclos menores de entrega do produto; ter produto com qualidade e confiabilidade; cumprir com a promessa de entrega; ser hábil, para produzir novos produtos rapidamente; possuir flexibilidade, para ajustar mudanças no volume; e obter custos baixos.

Após os trabalhos de Skinner, as prioridades competitivas se adaptaram ao novo ambiente e tornaram-se mais numerosas. Embora existam divergências entre algumas vantagens competitivas, algumas delas que ainda aparentam ser diferentes possuem aspectos, na base de seu conceito, de seu conteúdo e/ou de seu processo de formação, que demonstram entre si características muito semelhantes, apenas remodeladas pela forma como os autores concebem a organização e entendem o seu funcionamento.

Vários autores desenvolveram uma série de estudos com a finalidade de identificar as prioridades competitivas que a manufatura deve possuir para desenvolver e sustentar, a longo prazo, uma vantagem competitiva.

Rev. Adm. UFSM, Santa Maria, v. 4, n.1, p. 73-90, jan./abr. 2011 
Slack et al. (1997) definem cinco fatores que contribuem para a vantagem competitiva das organizações:

- confiabilidade, que significa produzir e entregar bens e/ou serviços, em tempo hábil e nos prazos prometidos, comunicar as datas com clareza ao cliente, fazer a entrega pontualmente;

- custo, que significa a capacidade de produzir bens e serviços a custos mais baixos do que os concorrentes conseguem administrar;

- flexibilidade, que significa ser capaz de atender a mudanças de produtos ou de serviços, a prazos de entrega, a volumes de produção, à ampliação ou à redução da variedade de produtos ou serviços,

- estar apto a mudanças quando for necessário e com a rapidez suficiente; qualidade, que significa fazer o que deve ser feito corretamente, entregar bens ou serviços conforme as especificações ou as necessidades dos clientes e fazer produtos que, realmente, os clientes desejam, sem cometer erros, e de boa qualidade;

- velocidade, que significa o tempo que o cliente deve esperar desde a emissão do pedido até o recebimento efetivo do produto.

Segundo os autores, ao alcançar esses cinco objetivos, a organização consegue patamares de superioridade no mercado.

Davis (2001) considera, além de custos, qualidade e flexibilidade, a entrega e o serviço como prioridades competitivas. A entrega vai ao encontro do fator rapidez, de Slack et al. (1997), pois diz respeito a fornecer produtos rapidamente. Já o serviço remete a como os produtos são entregues e acompanhados. $\mathrm{O}$ autor ainda destaca a tendência de prioridade que consiste no oferecimento de produtos que não agridam o meio ambiente e que sejam produzidos através de processos com a mesma característica.

Já Stevenson (2001) considera flexibilidade a capacidade de responder às mudanças. Tempo, a velocidade de melhoria dos processos, de desenvolvimento de novos produtos e de fornecimento ao cliente. A qualidade está relacionada com as perspectivas do comprador sobre quão bem o produto ou o serviço irá atender ao seu propósito. Preço é conceituado pelo autor como a quantia que um cliente deve pagar pelo produto ou pelo serviço. O autor considera ainda a diferenciação do produto uma prioridade competitiva, referindo-se a esta prioridade como sendo qualquer característica especial que leve um produto ou um serviço a ser percebido pelo comprador como mais adequado do que o do concorrente.

\section{METODOLOGIA}

Livros, periódicos e anais foram consultados para identificar quais os elementos que geram competitividade organizacional. Segundo Godoy (1999), a pesquisa documental é apropriada quando queremos estudar longos períodos de tempo, buscando identificar uma ou mais tendências no comportamento de um fenômeno.

No estudo, três etapas distintas foram realizadas para a identificação dos fatores geradores de competitividade.

Na primeira etapa, foram selecionados livros de Administração da Produção mais renomados no meio acadêmico. Buscou-se, nessa literatura, encontrar elementos ou objetivos considerados influentes na geração de competitividade. Para isso, observaram-se, no índice dos livros, títulos que remetiam a temas relacionados à vantagem competitiva. Dessa observação, foi possível selecionar os oito livros descritos no quadro 1. 
Posteriormente, leram-se os capítulos que tratavam do assunto. Esta leitura procurou extrair palavras ou termos que indicassem a geração de competitividade das organizações. A partir disso, criou-se uma tabela com os resultados encontrados, em que os capítulos foram organizados de acordo com grupos de autores que tinham aspectos em comum como geradores de competitividade.

Após esse primeiro levantamento, a segunda etapa buscou artigos em revistas acadêmicas e anais largamente conhecidos no meio acadêmico.

A busca foi realizada eletronicamente nos periódicos da Capes, no Portal Brasileiro da Informação Científica, indexados no Scielo, Gales, Emerald, Wilson, Sage, Science Direct, Inform e Ebsco. Para encontrar os artigos de interesse, restringiu-se a busca através das palavraschave: competitividade, desempenho, eficiência, eficácia, lucratividade, produtividade e performance.

Por meio de pesquisa eletrônica, foram consultados os artigos do período de 1994 a 2009 , conforme os critérios descritos anteriormente. A partir deste procedimento, foram encontrados 103 artigos em língua portuguesa e 296 artigos em língua inglesa. Selecionaram-se, para a análise de conteúdo, somente os trabalhos em língua portuguesa. Nesta análise, foi efetuada uma primeira leitura dos artigos. Esta leitura se deteve apenas nos resumos dos artigos, em que se buscava verificar se o artigo trataria de assuntos referentes à vantagem competitiva. Se no resumo não constasse este assunto, o artigo era desconsiderado. Os periódicos, os anais e os livros integrantes do material utilizado estão relacionados no quadro 1.

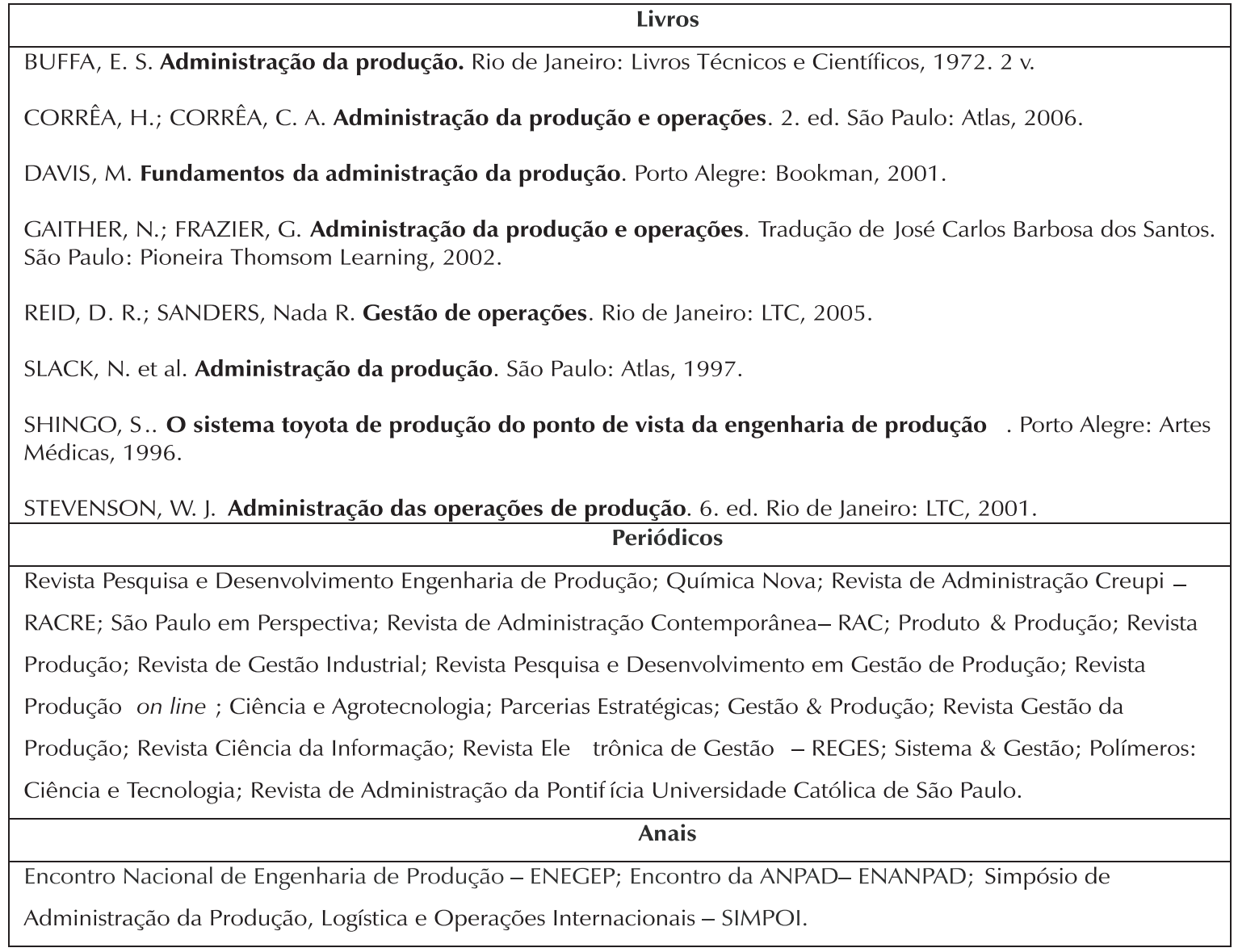

Quadro 1 - Livros, periódicos e anais utilizados na análise documental 
A partir dessa análise, identificou-se que 50 artigos tratavam exatamente do assunto em questão e apontavam componentes geradores de competitividade.

A terceira etapa procurou analisar os documentos para a extração de palavras-chave que influenciassem na geração de competitividade e de termos que afirmassem esta premissa. Os passos para análise dos documentos foram:

a. Leitura completa do documento;

b. Identificação das palavras-chave (fatores) geradoras de competitividade. Para a escoIha da palavra-chave, ela deveria seguir uma das seguintes diretrizes:

- aumenta a produtividade,

- melhora a performance,

- significa vantagem competitiva,

- aumenta a eficiência/eficácia;

c. Identificação do trecho do artigo que justificava a geração de competitividade por determinado fator;

d. Criação de uma planilha para a organização dos dados, contendo a palavra-chave (fator), a justificativa da palavra-chave e a referência. A justificativa foi escolhida através da interpretação de passagens do texto, sendo escolhida a mais representativa para a geração de competitividade.

No total, foram encontradas 107 palavras ou fatores geradores de competitividade. Em seguida, procedeu-se à análise desses fatores.

\section{ANÁLISE E RESULTADOS}

Com os resultados encontrados, foi possível agrupar os fatores de acordo com semeIhanças nas mensagens expressas de competitividade e com indicações de uma mesma lógica de conceito. Por exemplo: se o artigo pesquisado apresenta, como fator de competitividade, processos e produtos ecologicamente corretos, a lógica que fundamenta estes princípios é a da responsabilidade ecológica; se visa a fatores como tecnologia de ponta ou modernidade de instalações, sua lógica de competitividade está na tecnologia. Dessa forma, encontraram-se 14 (quatorze) grupos de fatores: flexibilidade, custo, confiabilidade, rapidez, relacionamento com clientes, qualidade, tecnologia, integração, responsabilidade ecológica, inovação, benchmarking, produção enxuta, treinamento e informação. Estes grupos, juntamente com seus fatores associados, estão demonstrados no quadro 2.

Nesse sentido, a primeira característica ou lógica verificada consiste na tendência dos textos de apresentar uma preocupação com o novo cenário mundial enfrentado pelas organizações. Nesse contexto, torna-se vital o papel de um recurso sempre presente nas empresas, mas que agora ganha cada vez mais destaque, a informação. Além disso, esse cenário caracterizase pelo desaparecimento das fronteiras entre empresas concorrentes, em que o espaço já não é uma barreira de entrada para novos competidores. Isso se deve, em grande parte, aos avanços decorrentes da utilização das tecnologias da informação e da comunicação. Essas tecnologias diminuíram consideravelmente os custos de transação envolvidos na relação entre os agentes econômicos. Significa dizer que houve maior conexão entre as pessoas, os processos e as organizações, devido à melhoria na comunicação do sistema como um todo. Assim, foi possível notar, nos textos pesquisados, termos como, por exemplo: ambiente informacional, conhecimento, arquitetura da informação, tecnologia da informação, comunicação, internet, estraté- 
gia, orientação estratégica, planejamento estratégico de recursos humanos, e gestão do conhecimento. Os autores desses artigos acreditam que tais fatores são essenciais na busca das organizações por competitividade.

\begin{tabular}{|c|c|}
\hline Fatores & Fatores relacionados \\
\hline Informação & $\begin{array}{l}\text { Ambiente informacional, conhecimento, arquitetura da informação, tecnologia da informação, } \\
\text { comunicação, internet, estratégia, orientação estratégica, planejamento estratégico de recursos } \\
\text { humanos e gestão do conhecimento. }\end{array}$ \\
\hline Flexibilidade & Troca rápida de ferramentas e eficiência dos equipamentos. \\
\hline Integração & $\begin{array}{c}\text { Relação com fornecedores, internacionalização, redes interorganizacionais, redes e eficiência } \\
\text { coletiva. }\end{array}$ \\
\hline Custo & Custos da qualidade, custo/preço, gerenciamento de custos e preço. \\
\hline Rapidez & Tempo de setup, entrega e tempo. \\
\hline Qualidade & Qualidade dos produtos, melhoria e aperfeiçoamento contínuos. \\
\hline Inovação & $\begin{array}{l}\text { Atividades inovadoras, pesquisa e desenvolvimento, inovação tecnológica, diferenciação de } \\
\text { produtos e novos produtos. }\end{array}$ \\
\hline Produção enxuta & $\begin{array}{l}\text { Gestão eficiente, tempo de setup, troca rápida de ferramentas, eficiência dos equipamentos, } \\
\text { melhoria contínua, programação puxada, definição de valor, geração de fluxo e cadeia de } \\
\text { valor. }\end{array}$ \\
\hline $\begin{array}{l}\text { Responsabilidade } \\
\text { Ecológica }\end{array}$ & $\begin{array}{l}\text { Produção mais limpa, desenvolvimento sustentável, gestão ambiental, eficiência no tratamento } \\
\text { de resíduos, riscos socioambientais, tecnologias mais limpas, produtos e processos } \\
\text { ecologicamente corretos. }\end{array}$ \\
\hline $\begin{array}{l}\text { Relacionamento com } \\
\text { cliente }\end{array}$ & $\begin{array}{l}\text { Satisfação do cliente, satisfação do consumidor, necessidades do cliente, conduta social, } \\
\text { consumo dos clientes, segmentação de mercado, orientação para o mercado, diferenciação de } \\
\text { foco, serviço e atendimento. }\end{array}$ \\
\hline Treinamento & $\begin{array}{l}\text { Habilidades e experiência do trabalhador, qualidade de vida, ergonomia, atitude gerencial, } \\
\text { relações de trabalho, estrutura interna, capital humano, educação e atitude gerencial. }\end{array}$ \\
\hline Tecnologia & $\begin{array}{l}\text { Adaptação a novas tecnologias, inovação tecnológica, tecnologia da informação, } \\
\text { modernização de máquinas e métodos, liderança tecnológica, modernização e gestão } \\
\text { tecnológica. }\end{array}$ \\
\hline Confiabilidade & Relações com fornecedores e eficiência dos equipamentos. \\
\hline Benchmarking & $\begin{array}{c}\text { Gestão por indicadores de desempenho, medição de desempenho e gerenciamento de } \\
\text { custos. }\end{array}$ \\
\hline
\end{tabular}

Quadro 2 - Agrupamento

Percebe-se, também, nos textos pesquisados, a preocupação com a inovação nas organizações. Esse conceito é muito ligado às mudanças descritas anteriormente no cenário mundial. Para se manterem competitivas nessa nova ordem mundial, de constantes mudanças, as organizações precisam adotar posturas inovadoras em seus processos produtivos. Nesse contexto, foram citados termos como: atividades inovadoras, pesquisa e desenvolvimento, inovação tecnológica, diferenciação de produtos e novos produtos.

É relevante considerar a preocupação com a responsabilidade ecológica. Antes considerada apenas um elemento de imposição da lei, a preocupação com o meio ambiente nos processos produtivos vem ganhando destaque em textos que abordam formas de promover a 
competitividade. A adoção de medidas ambientalmente responsáveis pode melhorar o desempenho dos processos de manufatura e produtividade das organizações. Nesse sentido, foram encontrados termos como: produção mais limpa, desenvolvimento sustentável, gestão ambiental, eficiência no tratamento de resíduos, riscos socioambientais, tecnologias mais limpas, produtos e processos ecologicamente corretos.

A integração está fundamentada em princípios organizacionais que procuram articular um relacionamento com empresas concorrentes, distribuidores e fornecedores de matéria prima e de material, visando a distribuir riscos e a aumentar a capacidade de competição. Seus fatores refletem em: relação com fornecedores, internacionalização, redes interorganizacionais, redes e eficiência coletiva.

Outros fatores se mostraram fundamentados em princípios que procuram manter a organização em conformidade com os níveis tecnológicos atuais, com a expectativa dos clientes e com as técnicas mais avançadas de gestão e de produção. Eles estão ligados ao item tecnologia. Dentre os fatores que caracterizam estes princípios podem-se citar: adaptação a novas tecnologias, inovação tecnológica, tecnologia da informação, modernização de máquinas e de métodos, liderança tecnológica, modernização e gestão tecnológica.

A qualidade fundamenta princípios que procuram atender à expectativa dos clientes com relação a produtos e serviços e às necessidades técnicas da organização: redução de erros e custos relacionados. Seus indicadores revelam a maneira pela qual a organização obtém padrão de qualidade nos processos e nos produtos e atende às expectativas de seus clientes, por meio da adoção de programas de controle e redução de erros e imperfeições nos processos e nos produtos. Inclui a qualidade dos produtos, a melhoria e o aperfeiçoamento contínuos.

O item treinamento inclui os fatores: habilidade e experiência do trabalhador, qualidade de vida, ergonomia, atitude gerencial, relações de trabalho, estrutura interna, capital humano, educação e atitude gerencial. Estes princípios procuram demonstrar que os objetivos de uma organização serão alcançados com sucesso se estiverem voltados para as políticas de valorização do capital humano, através de treinamento e integração social dos indivíduos e de motivação. De acordo com Lima e Urbina (2002), existe um consenso no sentido de que a organização que não propiciar a seus membros condições para satisfação de suas necessidades enfrentará sérios problemas de desempenho e de eficiência.

Os princípios de rapidez estão fundamentados em trabalhar rapidamente. Vale dizer, fazer com que o intervalo de tempo entre o início do processo de fabricação e a entrega do produto ao cliente seja pequeno, menor do que aquele oferecido pela concorrência. Significa reduzir o lead time da empresa, ou seja, reduzir o fluxo de informações, de materiais e de operações (SLACK, 1997). Os fatores imbricados neste conceito são: tempo de setup, entrega e tempo.

Princípios organizacionais que intentam conhecer e satisfazer as necessidades e as expectativas dos clientes, bem como fidelizar o relacionamento com eles, dizem respeito ao relacionamento com clientes. Seus fatores revelam a importância dada a esse relacionamento e a preocupação da empresa em atender às suas expectativas e necessidades. São eles: satisfação do cliente, satisfação do consumidor, necessidades do cliente, conduta social, consumo dos clientes, segmentação de mercado, orientação para o mercado, diferenciação de foco, serviço e atendimento.

Fatores relacionados às ações tomadas no sentido de modificar os processos ou o próprio produto, em busca da redução do seu preço final, por meio da fabricação de produtos com poucos detalhes no acabamento, com maior funcionalidade, com formas mais simples e padro- 
nizadas e confeccionados com material mais barato indicam quais são os princípios de custo. Incluem-se nessa lógica: custos da qualidade, custo/preço, gerenciamento de custos e preço.

Já os fatores ligados à confiabilidade dizem respeito à relação com os fornecedores e à eficiência dos equipamentos, que seguem os princípios de manter a promessa dos prazos de entrega; ter um planejamento, para prevenir surpresas; controlar a ocupação dos recursos; e monitorar as atividades de produção.

Vários fatores encontrados podem ser considerados como mais ligados à produção enxuta da organização. São elementos que visem, por exemplo, à adoção de práticas relacionadas à diminuição do desperdício, à utilização eficiente dos recursos, à busca da melhoria contínua e à agregação de valor às etapas de produção. Podem ser considerados nesse grupo os fatores: gestão eficiente, tempo de setup, troca rápida de ferramentas, eficiência dos equipamentos, melhoria contínua, programação puxada, definição de valor, geração de fluxo e cadeia de valor.

Outro grupo de fatores encontrados se baseia em: gestão por indicadores de desempenho e medição de desempenho. Estes princípios estão baseados no conceito de comparação das operações da própria empresa com as operações de outras companhias, ou seja, a prática do benchmarking.

Quanto às constantes e repentinas mudanças do cenário organizacional, a flexibilidade parece ser a resposta para isso. A flexibilidade, também considerada um grupo de fatores, visa a desenvolver a capacidade rápida de resposta da organização às mudanças ambientais. Seus fatores são: troca rápida de ferramentas e eficiência dos equipamentos.

Portanto, a revisão da literatura sugere aspectos que merecem atenção quando se fala em competitividade. Tais aspectos puderam ser agrupados em ideias: flexibilidade, produção enxuta, benchmarking, custo, treinamento, relacionamento com clientes, qualidade, tecnologia, integração, confiabilidade, rapidez, responsabilidade ecológica, inovação e informação. Percebemos que muitos dos fatores incluídos em um determinado termo poderiam ser incluídos em outros grupos. Porém, devido à necessidade de se estabelecer padrões para facilitar a análise, optou-se pelos grupos detalhados anteriormente.

\subsection{Práticas $x$ resultados}

Por meio desses padrões ou perfis estabelecidos, foi possível perceber uma grande concentração dos fatores competitivos que se diferenciam em dois grandes grupos. A partir desta observação, pode-se fazer um novo agrupamento, baseado no conceito de prática e de resultados. O primeiro grupo representa os padrões ou os perfis de boas práticas organizacionais (treinamento, integração, tecnologia, responsabilidade ecológica, benchmarking, produção enxuta, informação e relacionamento com clientes), que refletirão no resultado.

Ambos os grupos, o de resultados e o de práticas, conferem desempenho à organização. O primeiro (resultados) tem características muito importantes, que, segundo Slack (1997), são vitais para a organização ser bem-sucedida a longo prazo e, portanto, ser altamente desejável.

Já as práticas são atitudes, esforços ou habilidades que a organização deve ter e que asseguram as características de resultado.

Entende-se por características de resultado aquelas capazes de proporcionar competitividade de forma direta à organização: os custos (baixos), a flexibilidade (de produto e processo, se alta), a confiabilidade (do produto em uso e da entrega, se alta), a rapidez (da 
entrega e da prestação do serviço, se alta), a qualidade (do produto e do processo, se alta) e a inovação (de produtos e de processos, se constante e despertadora de interesse).

A forma como as práticas são aplicadas configura os esforços adotados, capazes de compor as características de resultado (Quadro 3). Isto quer dizer, são o meio para o alcance dos resultados (flexibilidade, inovação, qualidade, confiabilidade, rapidez e custo).

\begin{tabular}{|l|l|}
\hline PRÁTICAS & RESULTADOS \\
\hline Produção enxuta & Flexibilidade \\
\hline Informação & Custo \\
\hline Tecnologia & Rapidez \\
\hline Responsabilidade ecológica & Qualidade \\
\hline Treinamento & Confiabilidade \\
\hline Relacionamento com clientes & Inovação (resulta das práticas) \\
\hline Integração (da empresa ao meio em que opera) & \\
\hline Benchmarking & \\
\hline
\end{tabular}

Quadro 3 - Práticas e resultados

Treinamento: a prática do treinamento leva à melhoria da qualidade (tanto de processo como de produto). É através da habilidade desenvolvida no treinamento que se possibilita a produção de produtos e serviços de alta qualidade. Isso inclui evitar erros, o que gera diminuição de custos. Também inclui projetar trabalhos que incentivem o pessoal a melhorar o trabalho em si, de forma a criar inovações nos processos que, consequentemente, podem gerar maior flexibilidade e qualidade à produção.

As práticas de treinamento também influenciam na rapidez. Uma vez que o treinamento permite gerar o conhecimento da sequência de atividades e a autonomia sobre uma ação a ser decidida, haverá uma consequente capacidade de responder rapidamente a possíveis problemas no processo produtivo, ocasionando uma maior velocidade de resposta ao trabalho.

O treinamento pode afetar a habilidade dos trabalhadores em modificar a natureza de suas atividades. A flexibilidade, portanto, pode ser consequência de práticas de treinamento. Por exemplo, o pessoal em uma fábrica de carros que tenha sido treinado em diversas tarefas (polivalência) e que use a rotatividade de tarefas em seu grupo de trabalho, são, em si, recursos flexíveis. Sua flexibilidade torna mais fácil para eles fazer uma variedade de modelos e também os torna mais adaptáveis, quando novos modelos são introduzidos (SLACK, 1997).

Todas as práticas de treinamento descritas acima terão efeito sobre a produtividade e, portanto, sobre os custos do produto final (ver Figura 1).

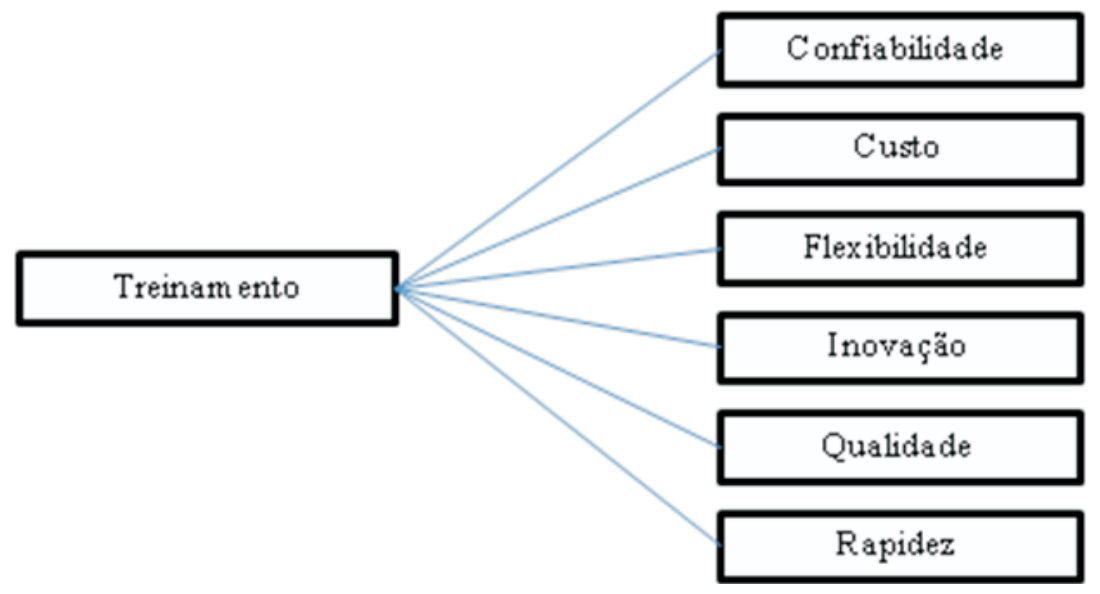

Figura 1 - Treinamento x resultados 
Integração: no que diz respeito à qualidade, os benefícios das práticas de integração derivam da proximidade da operação produtiva com seus clientes e seus fornecedores. Com a integração, é possível perceber mais facilmente a origem dos problemas, e, dessa forma, a solução pode ser concentrada no ponto mais adequado da rede.

Em relação à rapidez de entrega, práticas integradas podem significar uma sincronização mais próxima de programações, o que acelera a passagem de informações ao longo da rede (SLACK, 1997). Além disso, estar próximo de fornecedores e de clientes pode ajudar nas previsões. Isto reduz o risco de produzir produtos ou serviços para os quais a demanda nunca existirá.

Quanto à confiabilidade, melhor comunicação ao longo de uma rede integrada, que pode fazer melhores previsões, ela também pode resultar em promessas de entrega mais realistas. Mesmo quando os obstáculos significarem que as entregas não poderão ser efetuadas, haverá uma maior probabilidade de a empresa se antever ao problema, de forma que o cliente possa ser notificado no menor tempo possível.

Tratando-se da flexibilidade de novos produtos, as práticas de integração fornecem o potencial para guiar o desenvolvimento tecnológico (inovação) e para desenvolver produtos e serviços que atendam, mais específica e precisamente, às necessidades dos clientes.

Por fim, as práticas integradas podem proporcionar o potencial para o compartilhamento de alguns custos, como, por exemplo, a pesquisa e o desenvolvimento e a logística (ver Figura 2).

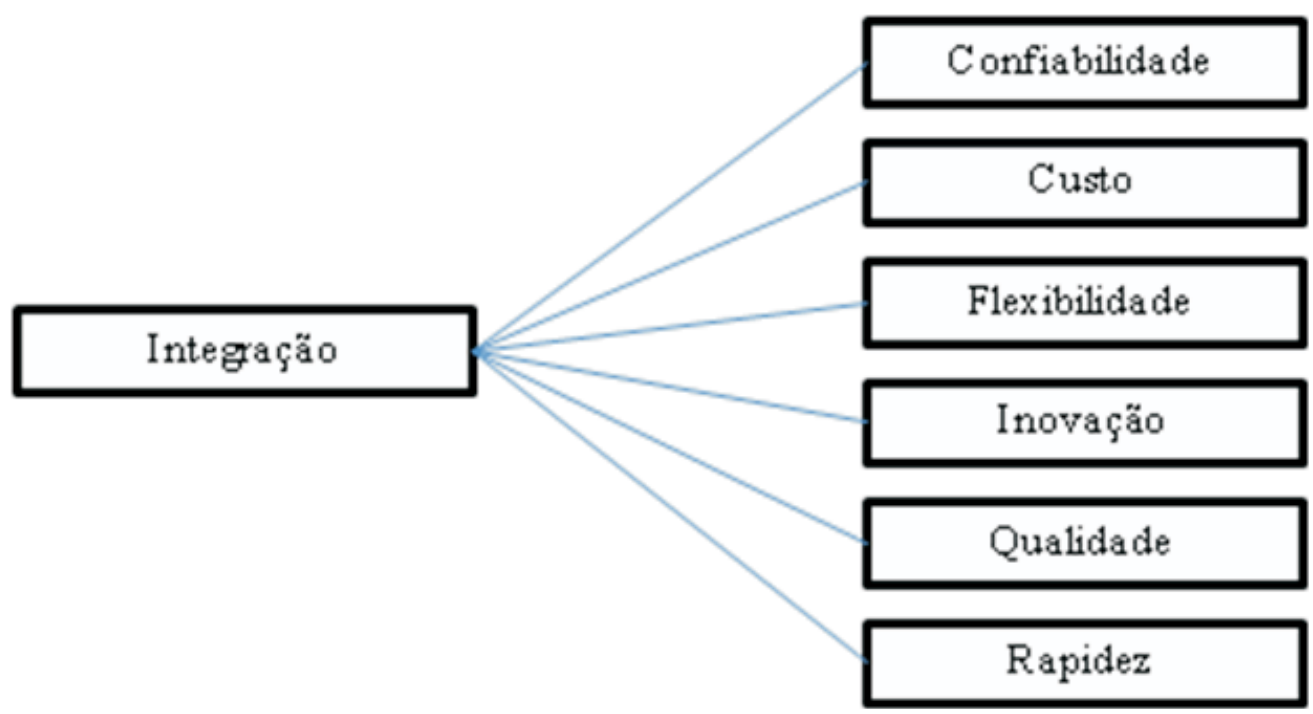

Figura 2 - Integração x resultados

Tecnologia: representa o conhecimento embutido em máquinas e presente nas pessoas. Tecnologias avançadas, portanto, podem levar à inovação de produtos e de processos e, consequentemente, à qualidade em todos os sentidos. Também o uso de equipamentos com tecnologias multifuncionais leva à maior flexibilidade, pois, através de um mesmo equipamento, é possível produzir diferentes famílias de produtos.

Quanto ao custo, com o uso de tecnologias avançadas é possível diminuir o número de operações efetuadas e também o tempo de preparação das máquinas, o que garante economia na produção (ver Figura 3). 


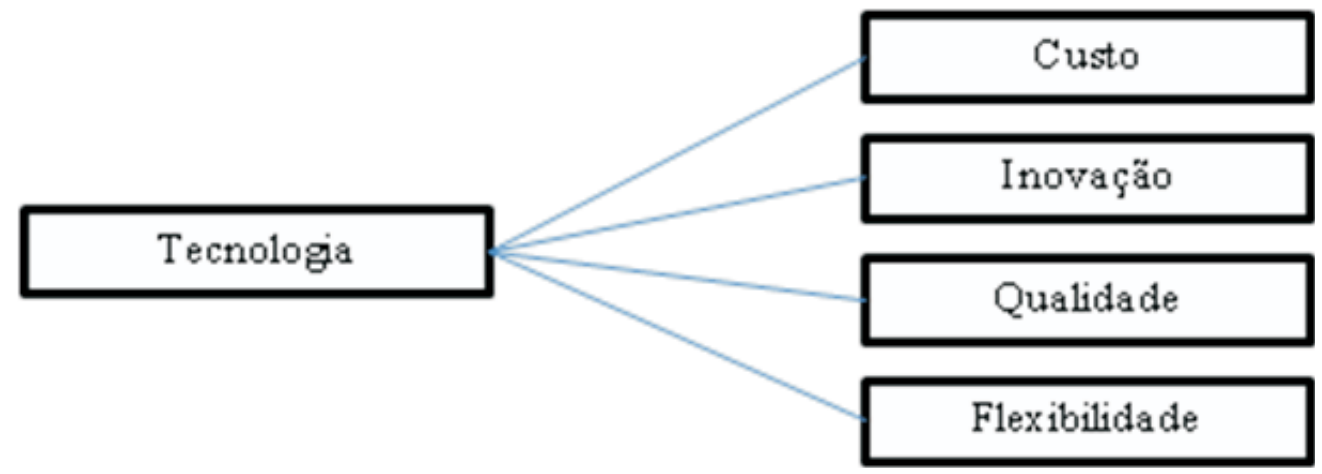

Figura 3 - Tecnologia x resultados

Relacionamento com o cliente: as práticas de relacionamento com o cliente se refletem em todos os fatores de resultado, pois é por meio da informação das necessidades do cliente que se molda a produção.

Dessa forma, haverá flexibilidade tanto no desenvolvimento de novos produtos (inovação), quanto na produção, com base nas informações dos desejos dos clientes, já que são eles que ditam o que produzir e quanto produzir.

Além disso, fazer produtos de qualidade é fundamental para que se crie uma relação de fidelidade com o cliente, pois, se o produto possui um custo/beneficio positivo na visão do consumidor, ele atende às suas necessidades, tornando-se um produto de qualidade.

Também é através das informações recebidas de práticas de relacionamento com os clientes que se desenvolvem, prioritariamente, os resultados. Por exemplo, se os consumidores valorizam preços baixos, a produção se dará por resultados que visem a ênfase de seu desempenho a baixo custo. Se os consumidores insistirem em produtos ou serviços isentos de erro, a produção concentrar-se-á em resultados de qualidade. A ênfase em entrega rápida tornará o critério rapidez importante para a produção, enquanto a ênfase em confiabilidade de entrega tornará o critério confiabilidade importante. Se uma gama de produtos ou serviços for exigida, a produção precisará ser suficientemente flexível para prover a necessária variedade, sem custo excessivo.

Portanto, são as práticas de relacionamento (ver Figura 4) com os clientes que influenciarão na busca por determinadas características de resultado.

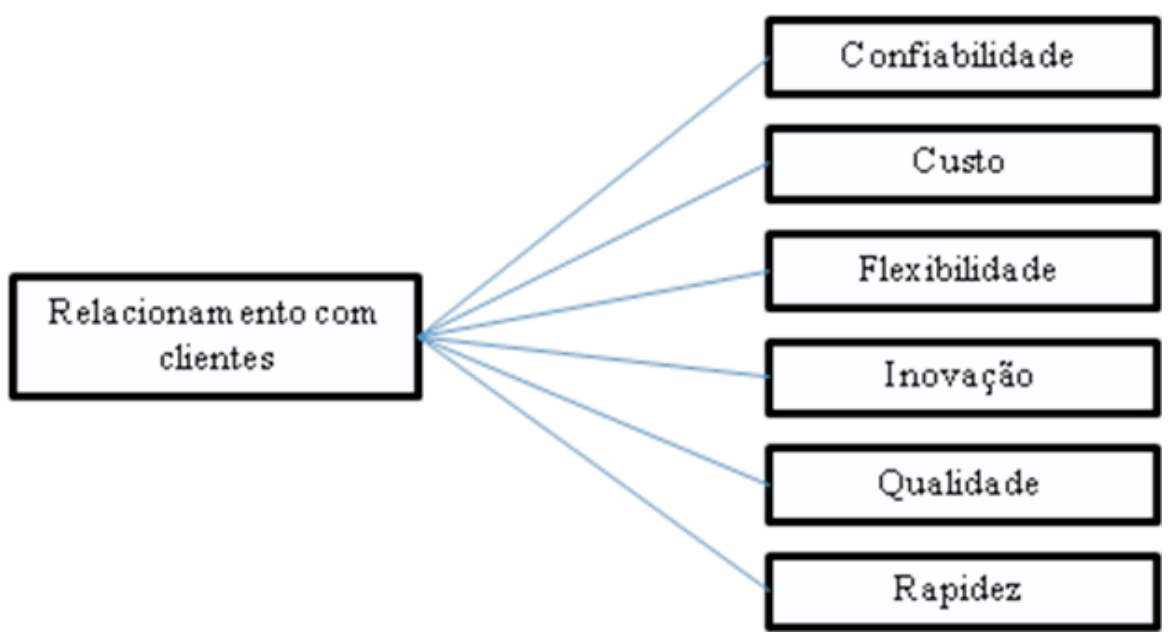

Figura 4 - Relacionamento com clientes x resultados 
Responsabilidade ecológica: são as práticas ecológicas que movem as empresas a adotarem novos métodos que reduzem os custos totais de um produto ou aumentam seu valor (DIAZ; PIRES, 2005). As práticas de responsabilidade ecológica geram resultados como: redução da quantidade de materiais e de energia utilizados, tornando assim os processos mais econômicos de maneira sustentável, ou seja, com menor custo; prevenção da poluição, gerando menos resíduos, efluentes e emissões, o que também ocasiona a redução de custos para a eliminação dos resíduos.

Outro exemplo relacionado à redução de custos é o uso dessas práticas durante a fase de criação de um projeto de produto. Isto porque, em um produto típico, 70\% dos custos de desenvolvimento são determinados na fase do projeto. Através da inclusão de considerações ambientais durante esta fase, podem-se aumentar a eficiência, reduzir os gastos de materiais e energia, reduzir os resíduos e, consequentemente, os custos. Da mesma forma, resíduos industriais, sejam eles sólidos, líquidos ou gasosos, podem ser reaproveitados na cogeração de energia, através de sua reciclagem, eliminando custos (LIMA; URBINA, 2002). Ainda, práticas desse grupo podem economizar em custos relacionados à implantação de equipamentos para o tratamento de poluentes.

Acredita-se que, com a adoção de práticas de responsabilidade ecológica, seja possível melhorar a performance dos processos de manufatura e a produtividade das organizações, através da inovação de processos e produtos. A busca constante pela redução dos impactos ambientais também pode levar à criação de uma cultura que procura a inovação dos processos continuamente, ou seja, a qualidade (DIAZ; PIRES, 2005).

Assim, essa prática leva as organizações a aumentar a sua produtividade através da reorganização e da melhoria dos processos produtivos, da análise do ciclo de vida e do projeto dos produtos, e da escolha e do uso mais eficiente dos recursos (matérias-primas, energia etc.). O aumento da produtividade através da aplicação desses conceitos (ver Figura 5) também é possível porque a poluição é, muitas vezes, um desperdício econômico, que, de alguma maneira, esconde problemas de planejamento, projeto, má utilização dos recursos etc. (LIMA; URBINA, 2002).

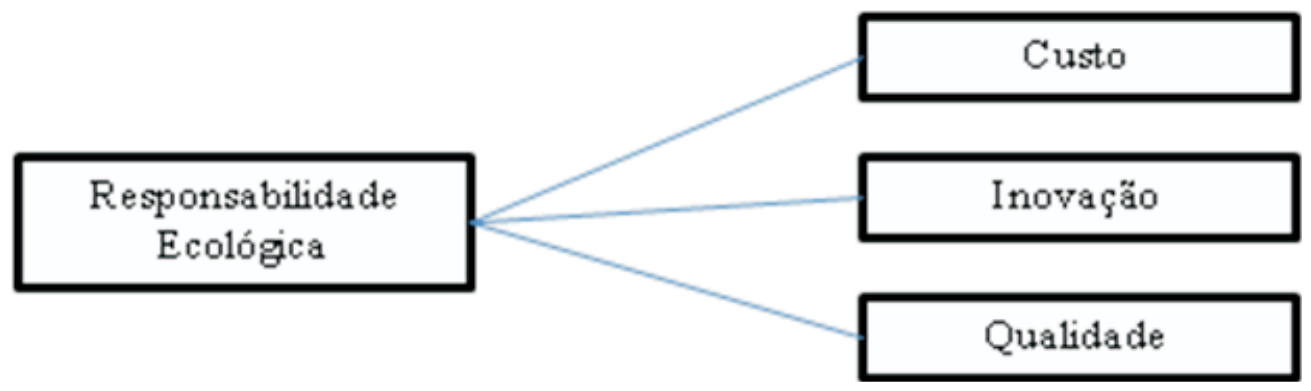

Figura 5 - Responsabilidade ecológica x resultados

Benchmarking: as práticas de benchmarking afetam todos os resultados (flexibilidade, custo, qualidade, inovação, confiabilidade e rapidez), pois se preocupam com a pesquisa de novas ideias e práticas, que podem ser copiadas ou adaptadas e que, portanto, podem afetar qualquer resultado, dependendo do que a empresa desejar (ver Figura 6). 


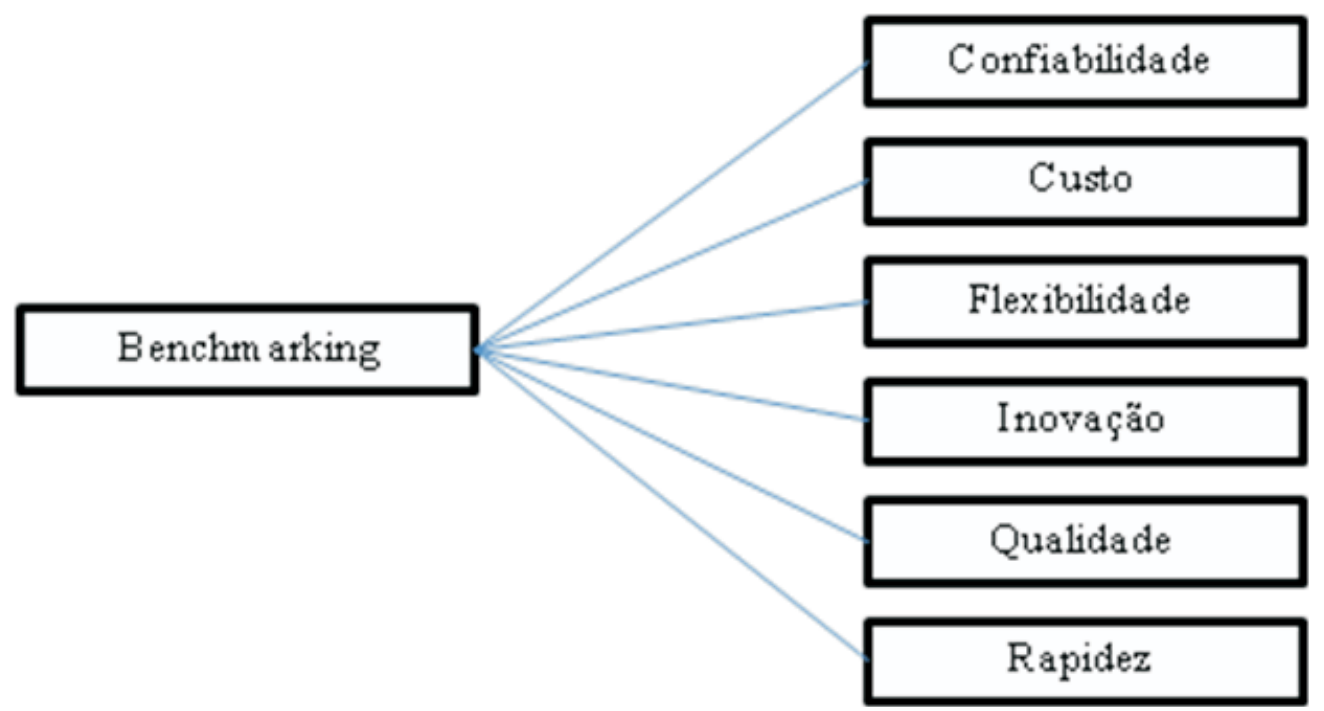

Figura 6 - Benchmarking x resultados

Informação: consiste em práticas que também afetam todos os resultados. Com informações apresentadas de modo a poderem ser utilizadas, é possível gerir os estoques, ditar o ritmo e a programação de atividades, prever a demanda, processar os pedidos no tempo certo e gerenciar a qualidade. Estas informações possibilitam o alcance de todos os resultados (ver Figura 7).

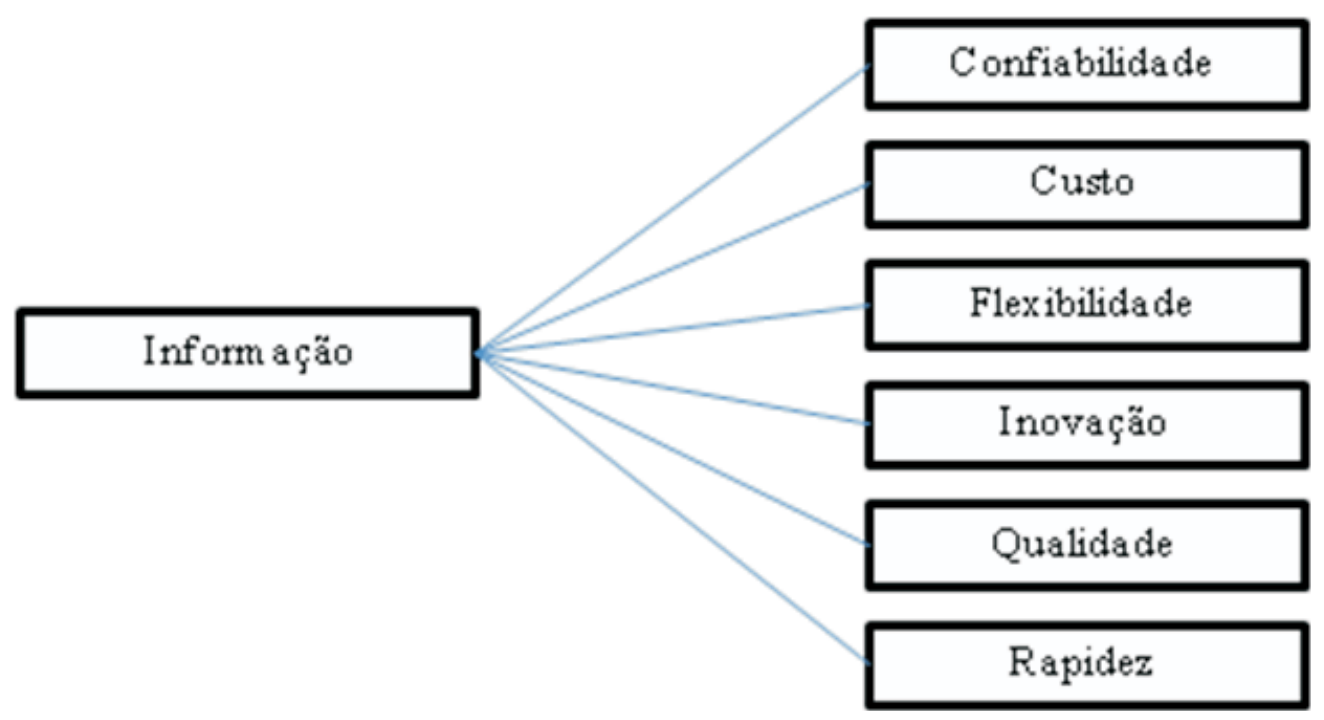

Figura 7 - Informação x resultados

Produção enxuta: as práticas de produção enxuta estão diretamente relacionadas com os princípios de qualidade, flexibilidade, custo, rapidez, confiabilidade e inovação (ver Figura 8). A base para o alcance destes resultados está nas práticas de produção puxada, fluxo contínuo, eliminação de desperdício e qualidade na fonte e na busca por melhorias contínuas (SHINGO, 1996).

Para que essas práticas atinjam seus objetivos, é necessário que a qualidade (de quem) seja alta, porque distúrbios na produção devido a erros de qualidade reduzirão o fluxo de 
materiais e a confiabilidade interna de fornecimentos, além de gerar o aparecimento de estoques, caso os erros diminuam a taxa de produção em algum ponto da operação.

A velocidade, em termos de rápido fluxo de materiais, é essencial caso se pretenda atender à demanda dos clientes diretamente com produção, em vez dos estoques.

A confiabilidade é um pré-requisito para o fluxo rápido ou, olhando por outro lado, é muito difícil atingir fluxo rápido se o fornecimento de componentes ou equipamentos não é confiável.

A flexibilidade é importante para que se consiga produzir em lotes pequenos, atingindo-se fluxo rápido e lead times curtos (SLACK, 1997).

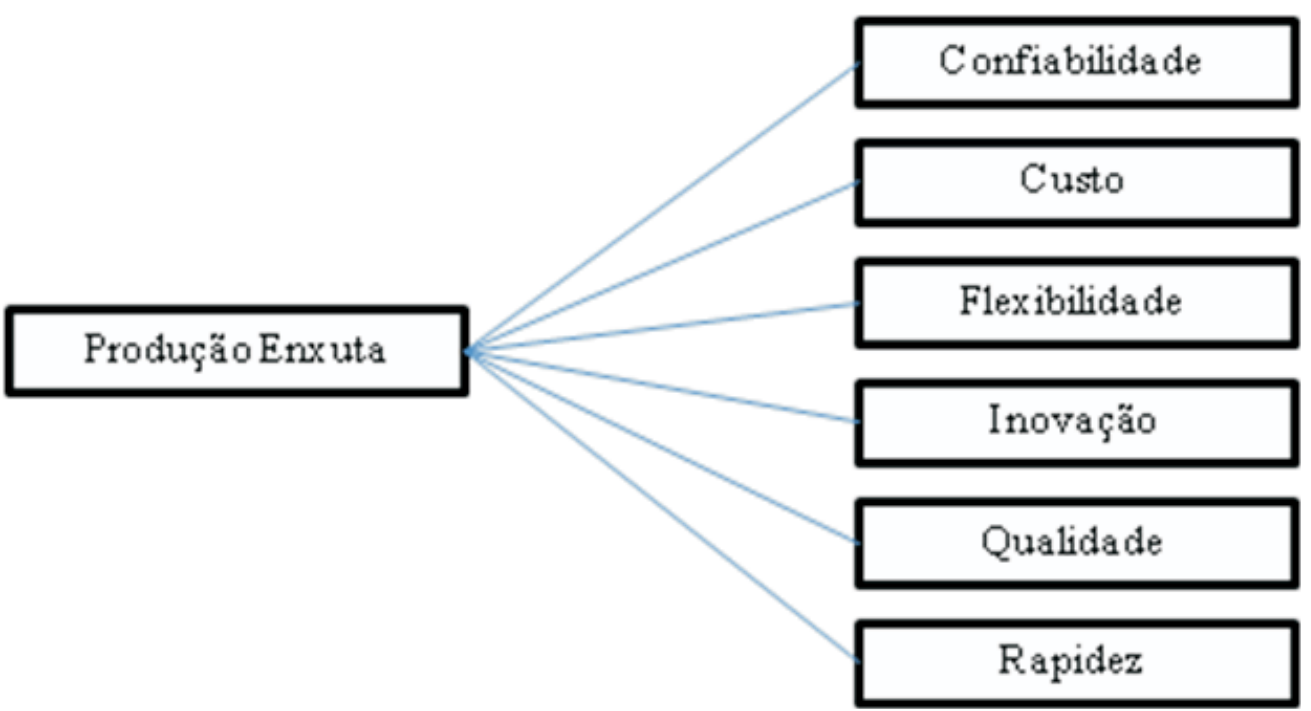

Figura 8 - Produção enxuta x resultados

A seguir, é apresentado o quadro 4, resumo da análise de práticas e resultados.

\begin{tabular}{|c|c|c|c|c|c|c|}
\hline . & Qualidade & Rapidez & Confiabilidade & Flexibilidade & Custo & Inovação \\
\hline Treinamento & $x$ & $\mathrm{x}$ & $x$ & $x$ & $x$ & $\mathrm{x}$ \\
\hline $\begin{array}{l}\text { Responsabilidade } \\
\text { ecológica }\end{array}$ & $x$ & & & & $x$ & $\mathrm{x}$ \\
\hline Informação & $x$ & $\mathrm{x}$ & $x$ & $x$ & $x$ & $\mathrm{x}$ \\
\hline Integração & $x$ & $x$ & $x$ & $x$ & $x$ & $\mathrm{x}$ \\
\hline $\begin{array}{l}\text { Relacionamento com } \\
\text { clientes }\end{array}$ & $x$ & $x$ & $x$ & $x$ & $x$ & $\mathrm{x}$ \\
\hline Tecnologia & $x$ & & & $x$ & $x$ & $\mathrm{x}$ \\
\hline Produção enxuta & $x$ & $x$ & $x$ & $x$ & $x$ & $\mathrm{x}$ \\
\hline Benchmarking & $x$ & $\mathrm{x}$ & $x$ & $x$ & $x$ & $\mathrm{x}$ \\
\hline
\end{tabular}

Quadro 4 - Resumo - Práticas x resultados

Além destas inter-relações de práticas e resultados, é possível notar que existem relações entre práticas e práticas e entre resultados e resultados. A título de exemplo, percebe-se que a flexibilidade influencia na confiabilidade, pois esta melhora através daquela, pelo fato de 
a flexibilidade ajudar a lidar com interrupções inesperadas no fornecimento. Entretanto, esta análise não será efetuada, e propõem-se pesquisas futuras nesse sentido.

\section{CONSIDERAÇÕES FINAIS}

O objetivo geral deste trabalho consistiu em identificar fatores, características ou aspectos essenciais para a geração de competitividade das organizações.

Desta pesquisa, puderam-se extrair 107 fatores geradores de competitividade, com as respectivas expressões que os associavam como influentes no desempenho das organizações. Estes fatores foram agrupados de acordo com uma mesma lógica de conceito. A classificação se deu em 14 (quatorze) grupos: treinamento, responsabilidade ecológica, produção enxuta, benchmarking, relação com clientes, tecnologia, informação, integração, confiabilidade, custo, inovação, flexibilidade, rapidez e qualidade.

Os grupos de fatores encontrados foram diferenciados em dois blocos que inter-relacionavam práticas e resultados. As práticas (treinamento, responsabilidade ecológica, produção enxuta, benchmarking, relação com clientes, tecnologia, informação e integração) se definem nas atitudes ou nos esforços que a organização deve ter para alcançar as características que conferem os resultados (confiabilidade, custo, inovação, flexibilidade, rapidez e qualidade).

Devido à proposta da pesquisa e ao seu tempo de execução, não puderam ser desenvolvidas, mais profundamente, outras relações, como, por exemplo, as relações entre fatores de práticas e entre fatores de resultado.

Entretanto, espera-se que os resultados encontrados sirvam de ponto de partida para aprofundamentos em outras pesquisas e em outros estudos na área. E, por fim, acredita-se que, com o aprofundamento dos estudos teóricos com o objetivo de retroalimentar o processo de desenvolvimento científico, podem-se prover os gestores de novas formas de administrar na dinâmica da sociedade atual.

\section{REFERÊNCIAS BIBLIOGRÁFICAS}

ALBUQUERQUE, A. S. et al. Aplicação da teoria das restrições e do indicador de eficiência global do equipamento para melhoria de produtividade em uma linha de fabricação. Revista de Gestão Industrial, v. 2, n. 1, p. 89-105, jan./mar. 2006.

ALVAREZ, D. et al. Produção mais limpa: integrando meio ambiente e produtividade. Produto \& Produção, Rio de Janeiro, v. 9, n. 2, p. 33-55, jun. 2008.

AMORIM, S. R. L. de; BANDEIRA, R. A. de M.; CÂNDIDO, G. A. Um sistema de indicadores para comparação entre organizações: o caso das pequenas e médias empresas de construção civil. Gestão \& Produção, São Carlos, v. 15, n. 2, p. 261-274, ago. 2008.
ARBIX, G.; DE NEGRI, J. A. A nova competitividade da indústria e o novo empresariado: uma hipótese de trabalho. São Paulo em Perspectiva, v. 19, n. 2, p. 21-30, abr./jun. 2005.

BARBOSA, F. V. Competitividade e performance de empresas. In: ENCONTRO ANUAL DA ANPAD, 11., 1997, Rio das Pedras. Anais... Cd-Room.

BARBOSA, S. de L.; MACHADO-DA-SILVA, C. L. Estratégia, Fatores de Competitividade e Contexto de Referência das Organizações: uma Análise Arquetípica. RAC - Revista Eletrônica, São Paulo, v. 6, n. 3, p. 7-32, set./dez 2002. 
BASSO, L. F. C.; PACE, ULRICH E. S.; SILVA, M. A. da. Indicadores de desempenho como direcionadores de valor. RAC - Revista Eletrônica, São Paulo, v. 7, n. 1, p. 37-65, jan./mar. 2003.

BUFFA, E. S.. Administração da produção. Rio de Janeiro: Livros Técnicos e Científicos, 1972. 2 v.

CALDAS, P. T.; VASCONCELOS, A. C. F. de; CÂNDIDO, G. A.. Tipologia de redes, estratégia e inserção competitiva: um estudo em um consórcio de empresas de base tecnológica. Revista Gestão Industrial, Curitiba, v. 3, n. 4, p. 14-27, 2007.

CARDOSO, D.; SOUZA, A. A. de. Benchmarking \& competitividade empresarial: o caso da área de laminação da Cia Siderúrgica Belgo Mineira. In: ENCONTRO NACIONAL DE ENGENHARIA DE PRODUÇÃO, 13., 1998, Rio de Janeiro, Anais... Cd-Room.

CARVALHO, F. de M.; FIÚZA, M. A.; LOPES, M. A. Determinação de custos como ação de competitividade: estudo de caso na avicultura de corte. Ciência e Agrotecnologia, Lavras, v. 32, n. 3, p. 908-913, mai. 2008

CARVALHO, J. L. M. de; TOLEDO, J. C. de. Produção mais limpa: integrando meio ambiente e produtividade. Polímeros: Ciência e Tecnologia, São Carlos, v. 12, n. 4, p. 240-247, 2002.

CASSANO, F. A.; AGUIAR, J. F. de. Estratégias competitivas para empresas brasileiras produtoras de tecidos planos: um estudo comparativo face à importação de produtos chineses. Reges, Picos, v. 1, n. 1, p. 86-99, nov. 2008.

CASTRO, M. de; SANTOS, F. C. A.; SILVA, E. M. da. $A$ relação entre prioridades competitivas e indicadores de desempenho: survey em empresas moveleiras. In: SIMPÓSIO DE ADMINISTRAÇÃO DA PRODUÇÃO, LOGÍSTICA E OPERAÇÕES INTERNACIONAIS, 11., 2008, São Paulo. Anais... Cd-Room.

COLETA, K. A. P. G.; DIAS, A. T.; GONÇALVES, C. A. Fatores Estratégicos e Desempenho de Empresas em Ambientes Turbulentos: o Caso das Companhias Brasileiras Abertas no Período 1996-2001. RAC Revista Eletrônica, São Paulo, v. 1, n. 3, p. 86-106, set. 2006.
CORRÊA, H.; CORRÊA, C. A. Administração da produção e operações. 2. ed. São Paulo: Atlas, 2006.

CORREIA, P. da C.; MANDELLI, I. A. M.; NICOLUCI, M. V. A inovação e a tecnologia a serviço de novos ganhos concorrenciais entre empresas. Revista de Administração Creupi - RACRE, Espírito Santo do Pinhal, v. 5, n. 9, p. 17-34, jan./dez. 2005.

COSTA, S. E. G. da; LIMA, E. P. de; VEIGA, G. L. Um sistema de indicadores para comparação entre organizações: o caso das pequenas e médias empresas de construção civil. Sistema \& Gestão Curitiba, v. 3, n. 2, p. 92-113, ago. 2008.

DAVIS, M.. Fundamentos da administração da produção. Porto Alegre: Bookman, 2001.

DEMARCHI, V.; HATAKEYAMA, K.; SOUZA, F. A. de. Indicadores de produtividade de ativos: ferramenta de auxílio no custeio da qualidade. In: ENCONTRO NACIONAL DE ENGENHARIA DE PRODUÇÃO, 22., 2007, Foz do Iguaçu. Anais.. Cd-Room.

DIAS, M. de C.. Modernização e produtividade do trabalho nos principais segmentos da indústria têxtil brasileira. Revista de Administração Creupi RACRE Espírito Santo do Pinhal, v. 11, n. 7, p. 153170, dez. 2007.

DIAZ, C. A. P.; PIRES, IGNÁCIO, S. R. Produção Mais Limpa: Integrando Meio Ambiente e Produtividade. Revista de Administração Creupi - RACRE, Espírito Santo do Pinhal, v. 5, n. 9, p. 51 57, jan. 2005

DUPONT, C. A. Fatores de competitividade da indústria brasileira de papel. Revista de Administração da Pontifícia Universidade Católica de São Paulo, São Paulo, v. 2, n.1, p. 114, 2000. Disponível em: < http://revistas.pucsp.br/ index.php/rad/article/view/1693/1087> . Acesso em: 20 jul. 2009

FERREIRA, G. C.; PERIN, M. G. A relação entre sucesso de novos produtos, orientação para o mercado e performance empresarial. Produto \& Produção, Local?, v. 9, n. 3, p. 85-94, out. 2008

FERREIRA, M. P. et al. Gestão por indicadores de desempenho: resultados na incubadora empresarial tecnológica. Produção, v. 18, n. 2, p. 302-318, mês? 2008. 
FLEURY, A. C. C.; FLEURY, M. T. L. Estratégias competitivas e competências essenciais: perspectivas para a internacionalização da indústria no Brasil. Gestão da Produção, São Paulo, v. 10, n. 2, p. 129144, ago. 2003.

FRANKLIN, M. A. et al. Arquitetura da informação e mensuração do desempenho: um estudo na indústria de artefatos e utensílios de plásticos no Estado de São Paulo. Gestão \& Produção, São Paulo, v.13, n.1, p. 151-165, dez. 2005.

FRANKLIN, M. A. et al. Ambiente informacional e desempenho competitivo na indústria de auto-peças para veículos. Revista Produção, v. 15, n. 3, p. 390403, set./dez. 2005.

FRONTINI, M. A.; LAURINDO, Fe. J. B.; VASCONCELLOS, E. P. G. Estudo de caso sobre gestão tecnológica e competitividade em uma operadora de telefonia móvel brasileira. Revista Produção on line, Florianópolis, v.8, n.3, 2008.

GAITHER, N.; FRAZIER, G. Administração da produção e operações. Tradução de José Carlos Barbosa dos Santos. São Paulo: (Pioneira?) Thomson Learning, 2002.

GODOY, A. S. Pesquisa qualitativa: tipos fundamentais. Revista de Administração de Empresas, São Paulo, v. 35, n. 3, p. 20-29, 1999.

HEINECK, L. F. M.; MACHADO, R. L. Modelos de produção enxuta destinados à viabilização de vantagens competitivas. In: ENCONTRO NACIONAL DE ENGENHARIA DE PRODUÇÃO, 11., 2001, Salvador. Anais... CD-Room.

LAURINDO, F. J. B. et al. Gestão da qualidade em serviços de TI: em busca de competitividade. Produção, São Paulo, n. 7, p. 329-340, ago. 2006.

LAURINDO, F. J. B.; SANTOS, S. L. dos. Fatores de suporte ao aumento da produtividade da tecnologia da informação. Revista Gestão Industrial, São Paulo, v. 1, n. 3, p. 101-112, 2005

LEMOS, A. D.; NASCIMENTO, L. F. A produção mais limpa como geradora de inovação e competitividade. RAC - Revista Eletrônica, v. 3, n. 1, p. 23-46, jan./ abr. 1999.
LIMA, C. S.; URBINA, L. M. S.. Eficiência competitiva através de investimentos em capital humano. In: ENCONTRO NACIONAL DE ENGENHARIA DE PRODUÇÃO, 12., 2002, São José Dos Campos. Anais... Cd-Room.

NETO, S. C.; PERERA, L. C. J. Fatores Essenciais para a Competitividade Internacional da Indústria Calçadista de Franca. In: ENCONTRO ANUAL DA ANPAD, 28., 2004, Curitiba. Anais... Cd-Room.

OLIVEIRA, C. L. C. et al.. Internet como fonte de vantagem competitiva: um caso na indústria portuária. Produção, v. 18, n. 3, p. 423-440, 2008.

OLIVEIRA, M. B. de. Análise dos impactos da troca rápida de ferramentas em pequenos lotes de fabricação: um estudo de caso. In: ENCONTRO NACIONAL DE ENGENHARIA DE PRODUÇÃO, 18., 2008, Rio de Janeiro. Anais... Cd-Room.

POLITZER, K. Aspectos e fatores da produtividade em pesquisa, desenvolvimento e inovação. Química Nova, Taubaté, v. 28, p. 76-88, 2005.

PRATES, G. A.. Reflexão sobre o uso da ergonomia aliado à tecnologia: Propulsores do aumento da produtividade e da qualidade de vida no trabalho. Revista de Administração, Espírito Santo do Pinhal, v. 7, n. 11, p. 76-85, nov. 2007.

REID, D. R.; SANDERS, N. R. Gestão de operações. Rio de Janeiro: LTC, 2005.

SCOPINHO, R. A.. Qualidade total e saúde e segurança no trabalho: o caso do setor sucroalcooleiro da região de Ribeirão Preto-SP. RAC, Curitiba, v. 4, n. 1, p. 93-112, jan./abr. 2000.

SILVA FILHO, A. R. A. da. Sistema de gestão ambiental como estratégia empresarial no ramo hoteleiro. Revista Produção on line, Florianópolis, v. 3, n. 8, p. 1-25, 2008.

SILVA, E. M. da; SANTOS, F. C. A. Análise do alinhamento da estratégia de produção com a estratégia competitiva na indústria moveleira. Produção, São Paulo, v. 15, n. 2, p. 286-299, mai./ jun. 2009.

SILVA, S. L. da. Informação e competitividade: a contextualização da gestão do conhecimento nos processos organizacionais. Ci. Inf., Brasília, v. 31, n. 2, p. 142-151, ago. 2002. 
SHINGO, S. O sistema Toyota de produção do ponto de vista da engenharia de produção. Porto Alegre: Artes Médicas, 1996.

SKINNER, W. Manufacturing: the missing link in corporate strategy. Harvard Business Review, v. 47, n. 3, p. 136-145, 1969.

SLACK, N. et al. Administração da produção. São Paulo: Atlas, 1997.

SOUZA, S. D. C. de; ARICA, J. Competitividade Industrial e Regional: Medidas e Dicotomias. In: ENCONTRO NACIONAL DE ENGENHARIA DE PRODUÇÃO, 12., 2002, Curitiba. Anais... CdRoom.
STEVENSON, W. J. Administração das operações de produção. 6. ed. Rio de Janeiro: LTC, 2001.

TERRA, J. C. C. Os desafios da produtividade: novas habilidades na era da gestão da informação e do conhecimento e o papel central da gestão do conhecimento. Parcerias Estratégicas, São Paulo, n. 5, p. 34-50, jul. 2005.

VEIGA, M. M. A competitividade e a gestão ambiental internacional de resíduos sólidos perigosos. Revista Pesquisa e Desenvolvimento Engenharia de Produção, n. 4, p. 67-80, fev. 2005. 